\title{
Endovascular occlusion of high-flow intracranial arteriovenous shunts: technical note
}

\author{
Willem Jan van Rooij • Menno Sluzewski
}

Received: 23 May 2007 / Accepted: 9 July 2007 / Published online: 6 September 2007

(C) Springer-Verlag 2007

\begin{abstract}
Endovascular closure of high-flow arteriovenous (AV) shunts in intracranial AV malformations or pial fistulas is technically challenging. In this paper, we illustrate two simple methods to occlude large high-flow AV shunts in a controlled manner.
\end{abstract}

Keywords AV shunt. Pial fistula AVM

\section{Introduction}

Endovascular closure of high-flow arteriovenous (AV) shunts in intracranial AV malformations (AVM) or pial fistulas is technically challenging [1-3]. With the use of liquid embolic agents, the high flow through the shunt may cause migration of the embolic agent to the venous outflow tract with possible devastating consequences. In anatomical configurations with a very short arterial feeder, the shunt can only be occluded at the venous side. In this paper, we illustrate two simple methods to occlude large AV shunts in a controlled manner applied in three patients.

\section{Case 1}

A 26-year-old man was referred for treatment after haemorrhage of a large callosal AVM (Fig. 1). Angiography demonstrated two high-flow AV shunts from the right anterior cerebral artery draining into enormously enlarged veins. Injection of Onyx 34 at the site of the largest shunt

W. J. van Rooij $(\bowtie) \cdot$ M. Sluzewski

Department of Radiology, St. Elisabeth Ziekenhuis,

Hilvarenbeekseweg 60,

5022 GC Tilburg, The Netherlands

e-mail: radiol@knmg.nl resulted in immediate migration to the venous side. Subsequently, a nondetachable microballoon (Magic B2, Balt, Montmorency, France) was flow-directed into the main feeder just proximal to the shunt and inflated to block the flow. At that time, Onyx injection was continued and resulted in gradual occlusion of the fistula in $7 \mathrm{~min}$. Next, the second high-flow shunt was occluded in a similar way. Control angiography confirmed complete occlusion of both AV shunts. A second embolization procedure was scheduled to be performed 3 months after the first.

\section{Case 2}

A 12-year-old boy was referred for treatment of a left frontal AVM discovered on MRI performed for seizures. Angiography under general anaesthesia demonstrated, besides a plexiform part of the nidus, two large AV shunts from the anterior cerebral artery (Fig. 2). The largest shunt had a very short arterial feeder that precluded the use of Onyx, since reflux would have led to migration into the normal vasculature. A microcatheter was navigated through the shunt into the proximal venous part and detachable coils were inserted until the shunt was completely occluded. Next, the second AV shunt was occluded with simple injection of Onyx 34 and continued injection occluded the major part of the nidus. After embolization, still under general anaesthesia, the patient was transferred to the Gamma Knife unit and the small AVM remnant was irradiated.

\section{Case 3}

A 27-year-old woman was referred for treatment of an intracranial vascular disorder that had been discovered on CT scan performed for chronic headaches. Vertebral 

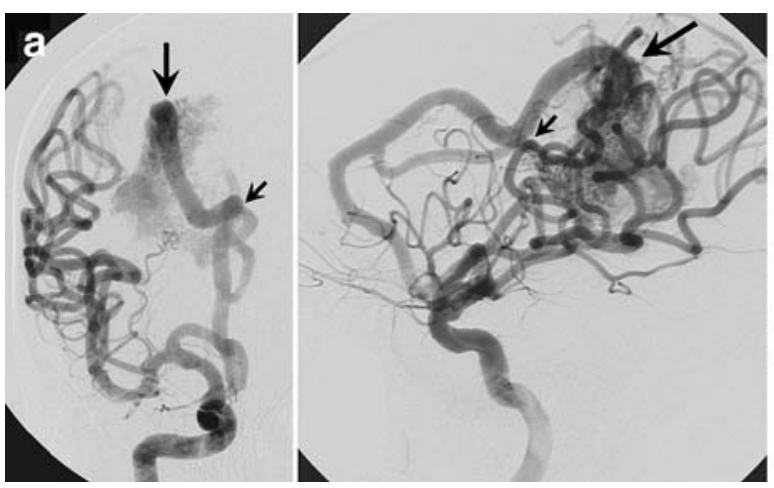

Fig. 1 A 26-year-old man with large callosal AVM. a Frontal and lateral right internal carotid angiogram shows an AVM with two highflow AV shunts from the anterior cerebral artery (arrows). b Lateral subtracted fluoroscopy image obtained during injection of Onyx with

angiography revealed a high-flow single-hole side-wall pial fistula from the P3-P4 segment of the right posterior cerebral artery draining into a dilated basal vein of Rosenthal (Fig. 3). In addition, a flow aneurysm on the right superior cerebellar artery was present. A microcatheter was navigated through the shunt into the vein and the proximal part of the vein was occluded with detachable coils with preservation of continuity of the posterior cerebral artery. Subsequently, the flow aneurysm was occluded with coils. A follow-up angiogram obtained 6 months later showed continuing closure of the fistula and the aneurysm.

\section{Discussion}

The most commonly used embolic agent in brain AVMs is the fast polymerizing liquid adhesive $n$-butylcyanoacrylate (NBCA, Histoacryl; Braun, Melsungen, Germany). Pure NBCA polymerizes immediately after contact with blood.
Slower polymerization is achieved when NBCA is mixed with iodinated oil (Lipiodol; Guerbet, Roissy, France). The use of a high concentration of NBCA or pure NBCA in high-flow shunts in brain AVMs may occlude the fistula within seconds, but this technique requires courage, experience and skill, since flow of NBCA is to some extent unpredictable [3]. Inadvertent migration of the glue into the draining veins may result in immediate haemorrhage by blocking venous outflow. Detachable coils may be inserted at the fistula site to decrease the flow and thereby facilitate the injection of NBCA [2]. Recently, the new liquid embolic agent Onyx has become available for embolization of brain AVMs (Onyx Liquid Embolic System; Microtherapeutics, Irvine, Calif.). Onyx is nonadhesive and polymerizes slowly. Onyx is available in several concentrations and the high-concentrated Onyx can be used to slowly occlude large AV shunts or pial AV fistulas in a more controlled way than that achieved with NBCA [4]. However, simple Onyx injection is not always feasible: in some very high-flow shunts Onyx may migrate through the fistula into the distal draining veins. We found the adjuvant
Fig. 2 A 12-year-old boy with a left frontal AVM. a Lateral angiogram of the left internal carotid artery shows a large AV shunt with a very short arterial segment (arrow). b Lateral angiogram obtained after occlusion of the venous and arterial side of the shunt with detachable coils
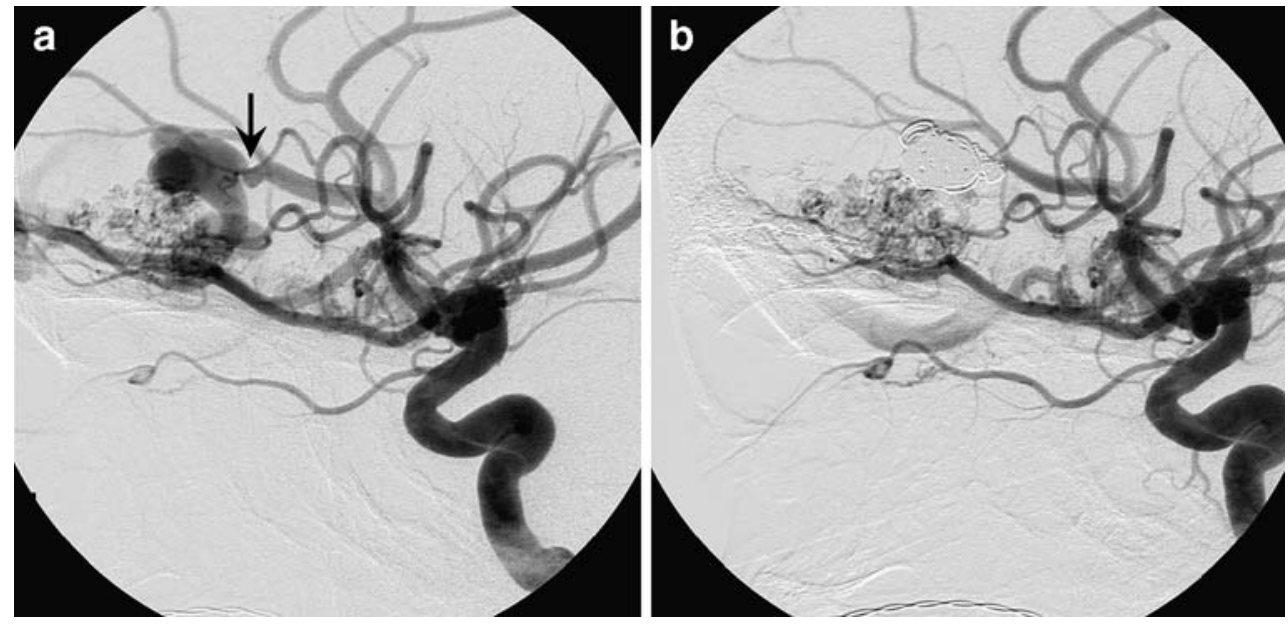
Fig. 3 A 27-year-old woman with pial fistula. a Frontal vertebral angiogram shows a highflow single-hole side-wall pial fistula from the P3-P4 segment of the right posterior cerebral artery draining into a dilated basal vein of Rosenthal. In addition, a flow aneurysm of the superior cerebellar artery is present (arrow). b Follow-up angiogram obtained 6 months after occlusion of the venous side of the fistula with detachable coils shows continuing occlusion of the fistula with preserved patency of the posterior cerebral artery
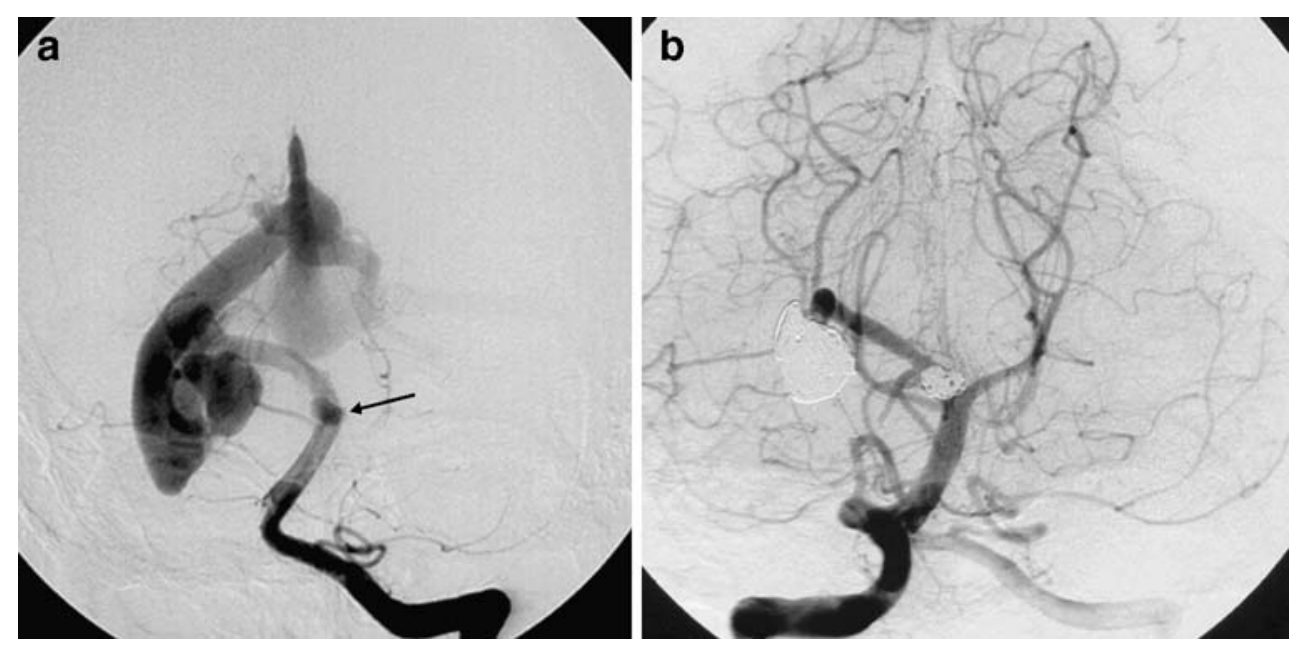

use of a microballoon to block the flow to enable gradual occlusion of the large high-flow shunts with Onyx in the AVM of patient 1 a very useful approach.

In the other patients, one with a very short arterial feeder of an AV shunt in an AVM and one with a side-wall pial fistula, the use of liquid embolic agents was not possible and controlled delivery of detachable coils to the venous side of the shunt was technically easy with complete occlusion of the fistula. This technique is helpful in shunts with a moderately dilated venous outflow tract in which placement of coils is possible.

In conclusion, different types of high-flow AV shunts can safely be occluded with endovascular techniques tailored to the specific anatomical configuration of the shunt.
Conflict of interest statement We declare that we have no conflict of interest.

\section{References}

1. Hoh BL, Putman CM, Budzik RF, Ogilvy CS (2001) Surgical and endovascular flow disconnection of intracranial pial single-channel arteriovenous fistulae. Neurosurgery 49:1351-1363

2. Nesbit GM, Barnwell SL (1998) The use of electrolytically detachable coils in treating high-flow arteriovenous fistulas. AJNR Am J Neuroradiol 19:1565-1569

3. Weon YC, Yoshida Y, Sachet M et al (2005) Supratentorial cerebral arteriovenous fistulas (AVFs) in children: review of 41 cases with 63 non choroidal single-hole AVFs. Acta Neurochir (Wien) 147:17-31

4. van Rooij WJ, Sluzewski M, Beute GN (2007) Brain AVM embolization with Onyx. AJNR Am J Neuroradiol 28:172-177 